\title{
The Impact of Occupation and Gender on Pensions from Defined Contribution Plans
}

\author{
David Blake ${ }^{\mathrm{a}}$, Andrew Cairns ${ }^{\mathrm{b}}$ and Kevin Dowd ${ }^{\mathrm{c} *}$ \\ ${ }^{a}$ Pensions Institute, Cass Business School, 106 Bunhill Row, London EC1Y 8TZ, U.K. \\ E-mail: d.blake@city.ac.uk \\ ${ }^{\mathrm{b}}$ Maxwell Institute, Heriot-Watt University, Edinburgh, U.K. \\ ${ }^{\mathrm{c}}$ Centre for Risk and Insurance Studies, Nottingham University Business School, Nottingham, U.K.
}

We present simulation results for the likely pension outcomes for different definedcontribution (DC) pension plan members distinguished by occupation and gender. While our results suggest that key differences between outcomes depend on the strategic asset allocation strategy chosen (and hence on the rate of return on assets in relation to the growth rate in salaries), we also find that DC plans benefit most those workers who have the highest career average salary relative to final salary or whose salary peaks earliest in their careers. Thus low-skilled workers and women do relatively well from DC plans: the largest median pension difference between occupations is 34 per cent (for men) and 38 per cent (for women), while the largest median pension difference between women and men in the same occupation is 45 per cent (for the same contribution rate). We conclude that key aspects of plan design (in particular contribution rates) should be occupation- and gender-specific.

The Geneva Papers (2007) 32, 458-482. doi:10.1057/palgrave.gpp.2510141

Keywords: pension plans; defined contribution; defined benefit; gender; occupation; career salary profile; peak salary age; strategic asset allocation; pension ratio

\section{Introduction}

Increasing numbers of people are joining defined-contribution (DC) pension plans, either because these are the only pension arrangements offered by their company or because their company has closed down its defined-benefit (DB) pension plan and transferred employees to a new DC plan. ${ }^{1}$ The plan members are typically offered a range of investment funds for their contributions. These vary from low risk to high risk and plan members are usually advised that high-risk funds will generate distributions of future pension values that have higher means and variances than those generated by low-risk funds. Plan members will then select an investment fund that reflects their attitude to risk.

\footnotetext{
* Kevin Dowd would like to thank the ESRC for financial support under grant RES-000-27-0014.

${ }^{1}$ By July 2007, 81 per cent of private-sector company DB pension schemes in the U.K. had closed to new members and 14 per cent had closed to additional contributions from existing members (Association of Consulting Actuaries (2007)). It is likely that DB will remain the predominant form of provision in the U.K. public sector for some time.
} 
However, little is known about the way in which occupation and gender influence the size of the pension. This is a significant shortcoming because different occupations have very different career salary profiles (CSPs). ${ }^{2}$ For example, professional sportsmen have steeply rising CSPs that peak at a very early age, while managers have less steeply rising CSPs that peak much later in their careers. There are also major differences between men and women in terms of their CSPs, even within similar occupational groups: women tend to have flatter CSPs that peak earlier than those of men. These considerations suggest that a "one size fits all" approach to pension plan design is inappropriate and that the "best advice" to any given DC plan member will be both occupation- and gender-specific.

This paper examines the impact of occupation and gender on the likely retirement income available from DC pension plans in the U.K. It builds on our earlier simulation studies of the accumulation and distribution phases of such plans using the PensionMetrics model. ${ }^{3}$ These studies investigated pension-fund outcomes using a variety of alternative assumptions for the distribution of investment returns, but only for the CSP of a "typical" male worker. They therefore ignored possible heterogeneities across occupation and gender: this paper seeks to fill this gap by systematically exploring the impact of such differences on prospective pension outcomes.

The layout of this paper is as follows. The following section sets out the model used in the study. The next section examines the CSP and shows that two of its key properties (the relative career average salary (RCAS) and the peak salary age (PSA)) are key determinants of pension outcomes. The following two sections present results for male and female workers respectively, taking account of occupational differences. The last section concludes.

\section{The PensionMetrics model}

We employ a modified version of the PensionMetrics model calibrated to U.K. data. ${ }^{4}$ This model uses stochastic simulation to determine the likely distribution of pension outcomes (measured in terms of the distribution of the pension ratio of actual DC pension to the pension from a final salary DB plan) for the plan member on his or her retirement date and then uses value-at-risk techniques to assess the desirability of these outcomes.

In order to identify the pure effect of the CSP on pension outcomes, we make the following assumptions. Both male and female workers join the pension plan at the age of 20 and retire at $60 .^{5}$ The pension at retirement is based on unisex annuity

\footnotetext{
2 Also known as a lifetime earnings profiles or age-earnings profiles.

${ }^{3}$ Blake et al. $(2001,2003)$.

${ }^{4}$ Blake et al. (2001).

${ }^{5}$ A retirement age of 60 matches the normal retirement age for women in the U.K. We could, as an alternative, have chosen a retirement age of 65 for both men and women, which would correspond to the normal retirement age for men in the U.K. Although some women do work between the ages of 60 and 65 , salaries after normal retirement age can be very different from pre-retirement salaries in most occupations. We wished to avoid any distortion to the female outcomes that might be induced by
} 
rates. ${ }^{6}$ To begin with, we also assume that each year the worker contributes 14 per cent of his or her earned income ${ }^{7}$ to a DC pension fund, and the contributions are invested according to one of four alternative strategic asset allocation (SAA) strategies discussed below. The annual returns on the assets in the pension fund are assumed to follow a multivariate normal stochastic process ${ }^{8}$ that is parameterised according to the realised real returns and volatilities on key U.K. and international securities over the post-war period. ${ }^{9}$ When the worker reaches the retirement age of 60 , the accumulated fund is converted into a single life annuity at the going market rate, which provides a level retirement income until death.

As a benchmark, we compare the prospective outcomes delivered by the DC pension plan against a DB pension plan paying a pension of two-thirds of final salary. ${ }^{10}$ To reflect this benchmark, our simulation results are expressed in terms of the pension ratio - the ratio of the DC pension to the pension that would be achieved in a conventional DB pension scheme with the same salary experience and duration of membership. A pension ratio equal to unity therefore implies that the DC pension plan has replicated exactly the same pension as the DB plan.

We model the accumulation phase of the pension fund under each of four alternative SAA strategies: ${ }^{11}$

- An "equities only" strategy: All contributions into the plan are invested in 100 per cent U.K. equities for the entire investment period.

- A "pension fund average" (PFA) strategy: A static strategy with the same portfolio weights over the entire investment period as the average U.K. DB occupational pension plan in 1998: 51 per cent U.K. equities, 5 per cent U.K. T-bills, 15 per cent U.K. bonds, 5 per cent U.K. property, 20 per cent international equities, and 4 per cent international bonds, with the latter two proxied by U.S. equities and bonds. ${ }^{12}$

including this age range in our analysis. We also wanted to compare men and women on as level a playing field as possible, hence we selected a common retirement age of 60 .

${ }^{6}$ The unisex annuity rates are based on a discount rate of 5 per cent and survival probabilities which are calculated as the arithmetic average of PMA92 and PFA92 survival probabilities from age 60; these are taken from mortality tables produced by the Faculty and Institute of Actuaries for males and females respectively and are based on the mortality experience of pension annuitants in the U.K. in the early 1990s. In practice, quoted male and female annuity rates for the same age differ, but the assumption was again chosen to preserve a level playing field. Over time, as male and female mortality rates move closer together and anti-discrimination legislation is introduced, the assumption becomes increasingly realistic.

7 The reason for this particular fixed rate is explained below.

${ }^{8}$ This was the simplest of the seven asset-return models considered by Blake et al. (2001). This study showed that the model for asset returns had considerably less impact on pension outcomes than the strategic asset allocation strategy selected.

${ }^{9}$ The same data period is used as in Blake et al. (2001), namely 1947-1998. See Appendix A for details of the properties of this data set.

${ }^{10}$ This is the maximum available pension in the U.K. from a DB plan with 40 years' continuous service on the basis of an annual accrual rate of $1 / 60$ th of final salary for each year of service. We assume for ease of comparability that all workers, both men and women, work continuously for 40 years.

${ }^{11}$ The first two can be classed as high risk, while the last two can be classed as low risk. Further details are provided in Blake et al. (2001).

12 We show below that the PFA strategy together with a 14 per cent contribution rate delivers a $2 / 3$ rds final salary pension with 95 per cent confidence to a typical female in the U.K. (see Table 10, column 3 ) and to 
- A "T-bills only" strategy: 100 per cent of the fund in U.K. T-bills for the entire investment period.

- A "bills-bonds" strategy: 50 per cent in U.K. T-bills and 50 per cent in U.K. bonds for the entire investment period. Blake et al. ${ }^{13}$ found that this strategy had the lowest risk of all those considered. With the exception of 100 per cent T-bills, the other strategies delivered higher average pension ratios but also wider spreads.

With this brief explanation of the PensionMetrics model, we can now move on to discuss the structure of CSPs.

\section{CSPs and their impact on pension outcomes}

The focus of this study is on the impact of gender and occupational differences on pension outcomes. We consider male and female workers classified both in very broad ways (i.e., "all occupations", "manual" and "non-manual") and in terms of the major occupational groups reported in the New Earnings Survey, namely, managers and administrators ("managerial"), professional occupations ("professional"), clerical and secretarial occupations ("clerical"), technical and associate professional occupations ("technical"), craft and related occupations ("craft"), personal and protective service occupations ("personal"), sales occupations ("sales"), plant and machine operatives ("plant operatives"), and other occupations ("other"). The CSP data are prepared by the Office for National Statistics (1998, Part F). The data measure average gross weekly salaries in pounds sterling and are reported for the following age ranges (with the central age for each age range reported in parentheses): below 18 (17), 18-20 (19), 21-24 (23), 25-29 (27), 30-39 (35), 40-49 (45), 50-59 (55), and 60-65 (63). Each CSP is therefore estimated using eight observations.

As Figures 1 and 2 show for men and women, respectively, the CSPs typically have a hump-shaped pattern for all occupations, reflecting the fact that real salaries generally rise initially with age and then subsequently fall. ${ }^{14}$ The CSPs have been rescaled to equal unity on the retirement date.

a typical male with slightly less confidence (see Table 5, column 3). This explains why we have selected a 14 per cent contribution rate for the DC plan.

13 Blake et al. (2001).

${ }^{14}$ We need to be cautious when interpreting CSP data. These data show the average weekly salaries for members of a particular occupation in different age ranges at a given point in time, relative to the final salary, stripping out productivity growth over the career (Samwick and Skinner (2004) use a similar approach for an analysis of $401(\mathrm{k})$ pensions plans in the U.S.). They do not show the CSP of a particular individual throughout his/her working life. While the latter data are what we ideally need, they are not available from official sources for a complete career (the New Earnings Survey Panel Dataset started in 1975 (Dickens (2000)). What the available data do show, for all occupations and both genders, is a hump-shaped pattern to real salaries over the working life with both the real starting and final salary being lower than the real salary in middle age. The rise in real salary to middle age is explained by the impact of merit increases and promotions early in the career. There are three key explanations as to why final real salaries are generally lower than real salaries in middle age. The first two are associated with selection effects. We might expect a proportion of individuals working in physically demanding or stressful jobs to switch into less demanding and less well-paid jobs within the same or possibly a different occupation later in life. We might also expect some retirement between ages 50 and 60 and it is likely that 
The Geneva Papers on Risk and Insurance - Issues and Practice 462

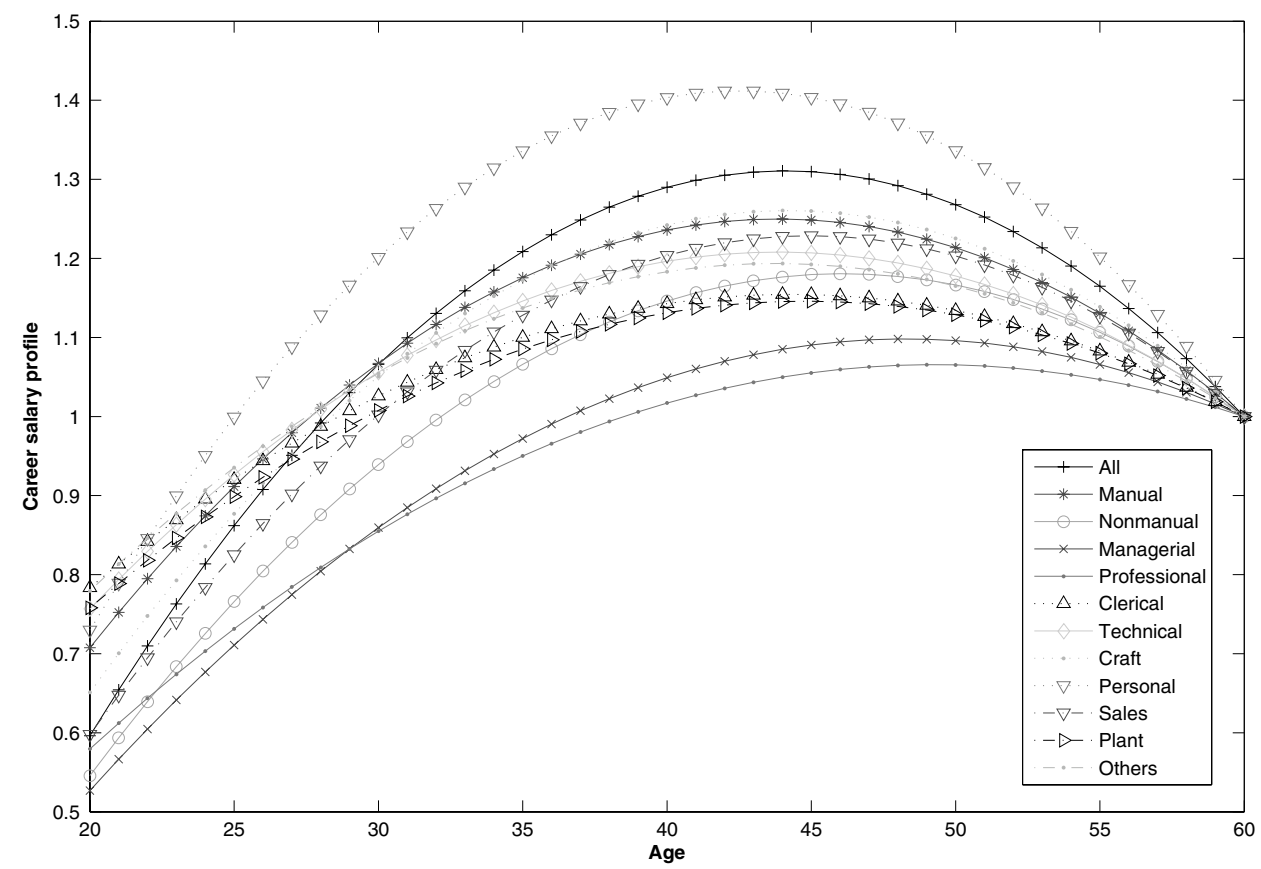

Figure 1. Career salary profiles for male workers.

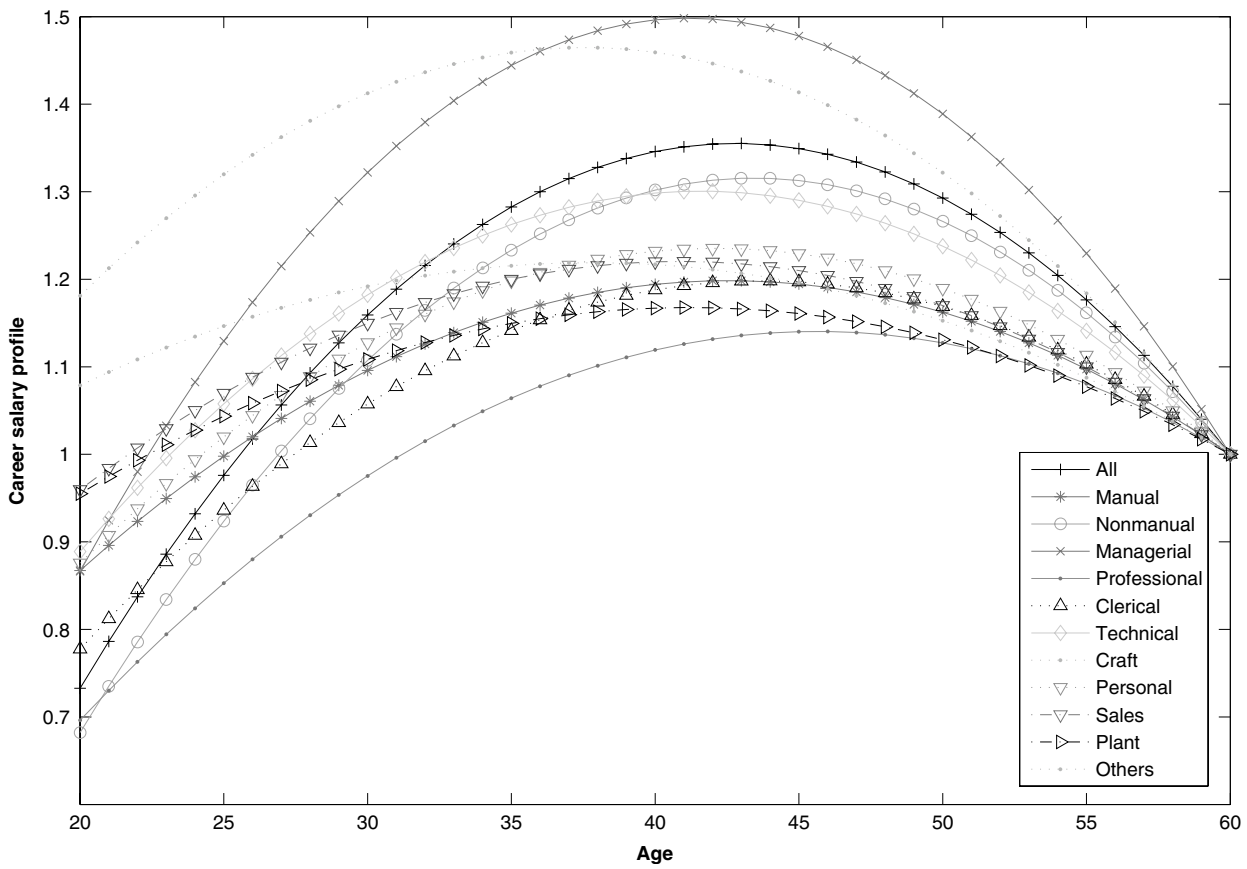

Figure 2. Career salary profiles for female workers. 
Two features of the CSP are key determinants of the pension outcome: the RCAS which is defined as the arithmetic average of the CSP over all ages relative to its final value of unity ${ }^{15}$ and the PSA.

An increase in the RCAS increases the pension ratio: the reason is that if contributions are salary-related, relatively higher contributions are invested earlier in the life of the scheme and this increases the size of the DC pension fund relative to the DB pension fund (i.e., the present value of the accrued pension benefits in the DB plan).

The effect of an increase in PSA depends on the relative sizes of the real return on assets $(r)$ and the real growth rate $(g)$ in salaries. In general, if $r>g$, an increase in PSA lowers the pension ratio. This is because a higher PSA, by increasing the curvature of the CSP, implies a lower starting salary and higher subsequent salaries (for the same RCAS). When $r>g$, the effect of a lower starting salary has a bigger impact on the size of the DC pension (in terms of lower cumulative returns, since $r$ is the return to the member in a DC plan) than it does for a DB pension (in terms of lower final salary, since $g$ is the "return" to the member in a DB plan). Since the pension ratio is the ratio of the DC to the DB pension, the pension ratio will generally fall under these circumstances. The opposite result holds, in general, when $r<g$. These results are proved in Appendix B

We also show in Appendix B that $R C A S$ and $P S A$ are functions of two parameters $k_{1}$ and $k_{2}$ that define the slope and curvature of the CSP:

and

$$
R C A S=1-0.5 k_{1}
$$

$$
P S A=20+40 \frac{k_{1}+4 k_{2}}{6 k_{2}}
$$

We are now in a position to examine how pension outcomes are determined for the different occupational groups listed at the beginning of this section, beginning first with those of males.

early retirees are typically the better-paid members of a particular occupation group at that age, leaving less well-paid members in work until the official retirement age. Finally, there is a cohort effect arising from the fact that the profiles are constructed from the salary data of different groups of workers at different ages, and the younger workers might be better educated than the older workers and hence have higher salaries.

${ }^{15} \mathrm{RCAS}$ is defined as follows:

$$
\begin{aligned}
R C A S & =\frac{1}{40} \sum_{x=20}^{59} \frac{w((x-20) / 40)}{w((60-20) / 40)} \\
& =\sum_{x=20}^{59} w\left(\frac{x-20}{40}\right) \\
& \doteq \int_{0}^{1} w(y) \mathrm{d} y / w(1)
\end{aligned}
$$

where $w(y)$ is the wage at rescaled age $y=(x-20) / 40$, normalised to ensure that $w((60-20) / 40)=w(1)=1$, assuming a starting age of 20 , a retirement age of 60 , and 40 years' continuous service. 
The Geneva Papers on Risk and Insurance - Issues and Practice

464

Table 1 Male career and salary profiles: parameters and key features

\begin{tabular}{|c|c|c|c|c|}
\hline Occupation & $k_{1}$ & $k_{2}$ & $\begin{array}{l}\text { Relative career } \\
\text { average salary }\end{array}$ & Peak salary age \\
\hline All & -0.2520 & 0.6557 & 1.126 & 44.10 \\
\hline Manual & -0.2171 & 0.5095 & 1.109 & 43.83 \\
\hline Non-manual & 0.0434 & 0.4976 & 0.978 & 47.25 \\
\hline Managerial & 0.0922 & 0.3810 & 0.954 & 48.28 \\
\hline Professional & 0.1176 & 0.3029 & 0.941 & 49.25 \\
\hline Clerical & -0.1183 & 0.3348 & 1.059 & 44.31 \\
\hline Technical & -0.1808 & 0.4240 & 1.090 & 43.82 \\
\hline Craft & -0.2067 & 0.5557 & 1.103 & 44.19 \\
\hline Personal & -0.4479 & 0.7180 & 1.224 & 42.51 \\
\hline Sales & -0.1375 & 0.5396 & 1.069 & 44.97 \\
\hline Plant operatives & -0.0944 & 0.3363 & 1.047 & 44.80 \\
\hline Others & -0.1707 & 0.3913 & 1.085 & 43.76 \\
\hline
\end{tabular}

Note: $k_{1}$ and $k_{2}$ are the slope and curvature parameters of the CSP and are explained in detail in Appendix B.

\section{Simulation results for males}

There are significant differences in the CSPs of the different male occupational groups listed in Figure 1, even though their shapes are broadly similar. ${ }^{16}$ These differences are reflected in the RCAS and PSA measures shown in Table 1. We find that RCAS is highest for personal-service and manual workers (with values of 1.224 and 1.109, respectively), and lowest for managers and professionals (with values of 0.954 and 0.941 , respectively). We also find that the PSA is lowest for personal-service workers (42.5 years) and highest for professionals and managers (49.3 and 48.3, respectively). Table 1 also presents estimates of the slope and curvature parameters $k_{1}$ and $k_{2}$ of the male CSPs.

Table 2 shows the simulated median pension ratio for male workers across the four SAAs. ${ }^{17}$ These results confirm our earlier 2001 findings for a "typical" male worker, namely that the equity-only and pension-fund-average strategies produce the highest median pension-ratios with the highest dispersions, and the bills-only and bills-bonds strategies produce the lowest median pension-ratios and dispersions across all occupational groups.

However, what is striking about the table is the wide dispersion of median pension ratios across occupations for the same SAA. To illustrate, for the equities-only strategy, the highest median pension ratio at 3.59 (for personal service workers) is 34 per cent higher than that of the lowest median pension ratio at 2.68 (for professionals) for the same contribution rate and asset returns. The same occupational groups come top and bottom for all the other SAAs and although the proportionate differences are smaller, they are nevertheless still significant. The explanation is clear. Personal-service

\footnotetext{
${ }^{16}$ Part of this similarity arises from restricting all the CSPs to be quadratic.

${ }^{17}$ All simulation results were based on 5,000 Monte Carlo simulations of the PensionMetrics model.
} 
Table 2 Male median pension ratios

\begin{tabular}{|c|c|c|c|c|}
\hline & Equities only & $P F A$ & T-bills only & Bills-bonds \\
\hline All & 3.23 & 2.58 & 0.87 & 0.88 \\
\hline Manual & 3.25 & 2.58 & 0.85 & 0.86 \\
\hline Non-manual & 2.72 & 2.18 & 0.76 & 0.77 \\
\hline Managerial & 2.69 & 2.15 & 0.74 & 0.75 \\
\hline Professional & 2.68 & 2.14 & 0.73 & 0.74 \\
\hline Clerical & 3.14 & 2.49 & 0.82 & 0.83 \\
\hline Technical & 3.22 & 2.56 & 0.84 & 0.85 \\
\hline Craft & 3.19 & 2.55 & 0.85 & 0.86 \\
\hline Personal & 3.59 & 2.86 & 0.94 & 0.95 \\
\hline Sales & 3.06 & 2.45 & 0.83 & 0.84 \\
\hline Plant operatives & 3.09 & 2.46 & 0.81 & 0.82 \\
\hline Others & 3.21 & 2.56 & 0.84 & 0.85 \\
\hline
\end{tabular}

workers (and indeed manual workers as a whole group) have the highest RCAS (lowest $k_{1}$ ) and the lowest PSA (highest $k_{2}$ ), whereas professionals have the lowest RCAS and highest PSA (see Table 1). Indeed, the ranking of median pension ratios over all occupational groups is very similar across the different SAAs, and again this follows from the relative sizes of RCAS and PSA.

Some occupational groups can end up with very similar median pension ratios across SAAs, however, even though they have very different RCASs and PSAs. An example in Table 2 is sales staff and plant operatives, and an examination of Table 1 shows how: sales staff have a low $k_{1}$ and a high $k_{2}$, while plant operatives have a high $k_{1}$ and a low $k_{2}$, and these various combinations happen to be such as to give almost identical pension ratios. ${ }^{18}$ In general, the median pension ratio is more sensitive to changes in $k_{1}$ than $k_{2}$. However, sensitivity to $k_{2}$ increases the further $r$ is from $g$. For example, in Table 2, the influence of $k_{2}$ is much smaller for the bills-bonds strategy where $r$ is very close to $g$, than with the PFA strategy where $r$ is much larger than $g .{ }^{19}$

Table 3 shows the corresponding likely worst pension-ratio outcomes at the 95 per cent confidence level: there is only a 5 per cent chance of receiving a pension ratio below these figures. The ranking of outcomes across occupations is similar for all the SAAs, with the best outcome being for personal-service workers and the worst outcome being for professionals across all SAAs. The SAA has a key influence on extreme outcomes. To illustrate, the equities-only strategy, while producing the best median pension outcomes across all occupations, generates the second worst tail outcomes after T-bills. By contrast, the PFA strategy produces the least worst tail outcomes.

\footnotetext{
${ }^{18}$ The second row of Eq. (B16) in Appendix B can be used to determine the combinations of $k_{1}$ and $k_{2}$ that give the same pension ratio.

${ }^{19}$ This is confirmed in Table B2 in Appendix B.
} 
Our results so far indicate that a high pension outcome is, ceteris paribus, associated with occupations with a high RCAS and/or a low PSA, although these features tend to go together in any case. Thus, for example, manual workers and especially personalservice workers can anticipate relatively good pension outcomes (as measured by the their pension ratios) because their CSP has a high peak that occurs early, and managerial and professional workers can anticipate relatively poor pension outcomes because their CSPs have low peaks that occur late.

We can gain further insight into the occupational differences by asking how contribution rates would differ across occupational groups if they are to achieve the same given prospective outcome. To illustrate, Table 4 shows the contributions required by each occupational group and for each SAA to give a 50 per cent chance that the pension ratio exceeds unity. High-risk, high-return strategies such as 100 per cent

Table 3 Male likely worst pension ratios ( $95 \%$ confidence level)

\begin{tabular}{|c|c|c|c|c|}
\hline & Equities only & $P F A$ & T-bills only & Bills-bonds \\
\hline All & 0.62 & 0.95 & 0.57 & 0.67 \\
\hline Manual & 0.61 & 0.94 & 0.56 & 0.65 \\
\hline Non-manual & 0.54 & 0.82 & 0.50 & 0.59 \\
\hline Managerial & 0.53 & 0.80 & 0.49 & 0.57 \\
\hline Professional & 0.53 & 0.80 & 0.48 & 0.56 \\
\hline Clerical & 0.59 & 0.90 & 0.54 & 0.62 \\
\hline Technical & 0.60 & 0.93 & 0.55 & 0.64 \\
\hline Craft & 0.61 & 0.93 & 0.56 & 0.65 \\
\hline Personal & 0.67 & 1.03 & 0.62 & 0.72 \\
\hline Sales & 0.59 & 0.90 & 0.55 & 0.63 \\
\hline Plant operatives & 0.58 & 0.89 & 0.53 & 0.62 \\
\hline Others & 0.60 & 0.92 & 0.55 & 0.64 \\
\hline
\end{tabular}

Table 4 Percentage contribution rate needed to give a 50\% chance that the male pension ratio exceeds unity

\begin{tabular}{|c|c|c|c|c|}
\hline & Equities only & $P F A$ & T-bills only & Bills-bonds \\
\hline All & 4.3 & 5.4 & 16.1 & 15.9 \\
\hline Manual & 4.3 & 5.4 & 16.4 & 16.2 \\
\hline Non-manual & 5.2 & 6.4 & 18.5 & 18.3 \\
\hline Managerial & 5.2 & 6.5 & 19.0 & 18.8 \\
\hline Professional & 5.2 & 6.5 & 19.3 & 19.0 \\
\hline Clerical & 4.5 & 5.6 & 17.2 & 17.0 \\
\hline Technical & 4.3 & 5.5 & 16.7 & 16.5 \\
\hline Craft & 4.4 & 5.5 & 16.5 & 16.2 \\
\hline Personal & 3.9 & 4.9 & 14.8 & 14.7 \\
\hline Sales & 4.6 & 5.7 & 17.0 & 16.8 \\
\hline Plant operatives & 4.5 & 5.7 & 17.4 & 17.1 \\
\hline Others & 4.4 & 5.5 & 16.8 & 16.6 \\
\hline
\end{tabular}


equities and the PFA require contribution rates well below 14 per cent, whereas lowrisk, low-return strategies, such as 100 per cent T-bills and bills-bonds require contribution rates in excess of 14 per cent. This clearly illustrates the so-called "reckless conservatism" of investing in low-return assets over long investment horizons. The table also shows the variation across occupational groups within the same SAA. For example, with 100 per cent equities, the required contribution rate is 3.9 per cent for personal-service workers, while for managers and professionals, it is 5.2 per cent, 33 per cent higher. With bills-bonds, on the other hand, the required rate for personal-service workers is 14.7 per cent, while for professionals it is 19 per cent, 29 per cent higher.

Whatever SAA is chosen, non-manual workers have to contribute much more than manual workers to achieve the same probability of doing as well as in a DB scheme. The choice between DB and DC schemes therefore has major redistributive implications between occupational groups. Managerial and professional workers do relatively well under DB schemes, since they have a high salary near retirement relative to their career average salary (this corresponds to a low RCAS and high PSA), and they do relatively badly under DC schemes. By contrast, manual workers do relatively well under DC schemes and relatively badly under DB ones. A switch from DB to DC schemes thus implies significant transfers of wealth, and in particular from managerial and professional workers to manual workers, relative to the pension outcomes the same workers would have experienced under a DB scheme.

Table 5 shows the required contribution rates needed to achieve the same likely worst pension ratios as the PFA strategy. All other strategies require higher contribution rates. In other words, a well-financed and well-diversified investment strategy with a high equity weighting not only provides an adequate pension on average, it also provides the least costly way of avoiding extremely poor outcomes. The table also shows that within each SAA, there is very little variation of required contribution rates across occupational groups: this is consistent with the findings in Table 3.

Table 5 Percentage contribution rate needed to achieve same likely worst male pension ratio as the PFA strategy $(95 \%$ confidence level)

\begin{tabular}{|c|c|c|c|c|}
\hline & Equities only & $P F A$ & T-bills only & Bills-bonds \\
\hline All & 21.44 & 14.00 & 23.11 & 19.88 \\
\hline Manual & 21.53 & 14.00 & 23.28 & 20.06 \\
\hline Non-manual & 21.11 & 14.00 & 22.80 & 19.55 \\
\hline Managerial & 21.15 & 14.00 & 23.00 & 19.71 \\
\hline Professional & 21.15 & 14.00 & 23.14 & 19.85 \\
\hline Clerical & 21.50 & 14.00 & 23.42 & 20.20 \\
\hline Technical & 21.59 & 14.00 & 23.39 & 20.17 \\
\hline Craft & 21.52 & 14.00 & 23.26 & 20.04 \\
\hline Personal & 21.65 & 14.00 & 23.31 & 20.12 \\
\hline Sales & 21.36 & 14.00 & 23.13 & 19.89 \\
\hline Plant operatives & 21.47 & 14.00 & 23.40 & 20.17 \\
\hline Others & 21.56 & 14.00 & 23.38 & 20.17 \\
\hline
\end{tabular}




\section{Simulation results for females}

Figure 2 shows that, as in the case of men, there are significant differences between the CSPs of different female occupations, although the differences are less than those for men. These differences are reflected in the RCAS and PSA values in Table 6: RCAS is highest for craft and managerial workers, and lowest for professionals; PSA is lowest for craft and other workers, and highest for professionals. By contrast with males, female RCASs are higher and PSAs are lower (since the $k_{1} \mathrm{~s}$ and the $k_{2} \mathrm{~s}$ are on average both lower than the male counterparts, cf. Table 1).

There are also significant cross-gender differences within the same occupational groups. For example, the RCAS of female personal-service workers is lower than that of their male colleagues, while female managers and professionals have higher RCASs than their male counterparts (cf. Table 1).

Table 7 shows the simulated median pension ratios for female workers. As with the male results, the equities-only and PFA strategies produce the highest and the T-bills-only and bills-bonds strategies produce the lowest median pension-ratios. However, there are significant cross-gender differences between the various occupations. For example, given an equity-only asset strategy, the two best performing female occupations are craft and other workers, whereas for men it is personal-service and technical workers. Female managers do particularly well in pension-ratio terms compared with their male counterparts. There are also some cross-gender similarities - for example, professional women do as relatively badly in terms of pension outcomes as their male counterparts. As in the case of males, the ranking of outcomes for the different occupations is broadly similar for each SAA. Table 8 shows the corresponding likely worst pension-ratio outcomes and the ranking across occupations for the various SAAs is very similar to Table 7, but, as in the case of males, the dispersion is much lower (cf. Tables 2 and 3).

Table 6 Female career and salary profiles: parameters and key features

\begin{tabular}{lcccc}
\hline Occupation & $k_{1}$ & $k_{2}$ & $\begin{array}{c}\text { Relative career } \\
\text { average salary }\end{array}$ & $\begin{array}{c}\text { Peak } \\
\text { salary age }\end{array}$ \\
\hline All & -0.3721 & 0.6393 & 1.186 & 42.79 \\
Manual & -0.2147 & 0.3475 & 1.107 & 42.55 \\
Non-manual & -0.2966 & 0.6144 & 1.148 & 43.45 \\
Managerial & & & & 41.19 \\
Professional & -0.6172 & 0.7508 & 1.309 & 45.60 \\
Clerical & -0.0576 & 0.3614 & 1.029 & 43.72 \\
Technical & -0.1764 & 0.3989 & 1.088 & 41.57 \\
Craft & -0.3610 & 0.4720 & 1.180 & 37.54 \\
Personal & -0.6728 & 0.4917 & 1.336 & 42.11 \\
Sales & -0.2680 & 0.3923 & 1.134 & 40.84 \\
Plant operatives & -0.2798 & 0.3202 & 1.140 & 41.19 \\
Others & -0.2077 & 0.2527 & 1.104 & 37.79 \\
\hline
\end{tabular}

Note: $k_{1}$ and $k_{2}$ are the slope and curvature parameters of the CSP and are explained in detail in Appendix B. 
Table 7 Female median pension ratios

\begin{tabular}{|c|c|c|c|c|}
\hline & Equities only & $P F A$ & T-bills only & Bills-bonds \\
\hline All & 3.48 & 2.77 & 0.91 & 0.92 \\
\hline Manual & 3.33 & 2.64 & 0.85 & 0.86 \\
\hline Non-manual & 3.34 & 2.66 & 0.89 & 0.90 \\
\hline Managerial & 3.91 & 3.11 & 1.01 & 1.02 \\
\hline Professional & 3.01 & 2.39 & 0.79 & 0.80 \\
\hline Clerical & 3.22 & 2.56 & 0.84 & 0.85 \\
\hline Technical & 3.55 & 2.82 & 0.91 & 0.92 \\
\hline Craft & 4.16 & 3.29 & 1.02 & 1.03 \\
\hline Personal & 3.41 & 2.70 & 0.87 & 0.88 \\
\hline Sales & 3.46 & 2.75 & 0.88 & 0.89 \\
\hline Plant operatives & 3.36 & 2.66 & 0.85 & 0.86 \\
\hline Others & 3.59 & 2.83 & 0.89 & 0.90 \\
\hline
\end{tabular}

Table 8 Female likely worst pension ratios (95\% confidence level)

\begin{tabular}{|c|c|c|c|c|}
\hline & Equities only & $P F A$ & T-bills only & Bills-bonds \\
\hline All & 0.65 & 1.00 & 0.60 & 0.70 \\
\hline Manual & 0.61 & 0.94 & 0.56 & 0.65 \\
\hline Non-manual & 0.63 & 0.97 & 0.58 & 0.68 \\
\hline Managerial & 0.71 & 1.10 & 0.66 & 0.76 \\
\hline Professional & 0.57 & 0.87 & 0.52 & 0.61 \\
\hline Clerical & 0.60 & 0.92 & 0.55 & 0.64 \\
\hline Technical & 0.65 & 1.00 & 0.60 & 0.69 \\
\hline Craft & 0.73 & 1.14 & 0.67 & 0.77 \\
\hline Personal & 0.63 & 0.97 & 0.57 & 0.66 \\
\hline Sales & 0.63 & 0.97 & 0.58 & 0.66 \\
\hline Plant operatives & 0.61 & 0.95 & 0.56 & 0.64 \\
\hline Others & 0.64 & 0.99 & 0.58 & 0.67 \\
\hline
\end{tabular}

To evaluate how contribution rates would alter across occupational groups if they are all to achieve any given prospective outcome, Table 9 shows the contribution rates required by each occupational group and for each SAA to give a 50 per cent chance that the female pension ratio exceeds unity. The required contribution rates are generally lower than the corresponding male rates across all SAAs, reflecting the generally higher female RCASs and lower PSAs (cf. Table 4).

Table 10 shows the required contribution rates needed to achieve the same likely worst pension ratios as the PFA strategy. In this case, the female rates are in general slightly higher than the corresponding male rates across all SAAs (cf. Table 5). This suggests that the shape of the female CSPs, while delivering better median outcomes than male CSPs, also deliver marginally worse tail outcomes. 
The Geneva Papers on Risk and Insurance - Issues and Practice

470

Table 9 Percentage contribution rate needed to give a $50 \%$ chance that the female pension ratio exceeds unity

\begin{tabular}{|c|c|c|c|c|}
\hline & Equities only & $P F A$ & T-bills only & Bills-bonds \\
\hline All & 4.0 & 5.1 & 15.3 & 15.1 \\
\hline Manual & 4.2 & 5.3 & 16.4 & 16.3 \\
\hline Non-manual & 4.2 & 5.3 & 15.8 & 15.6 \\
\hline Managerial & 3.6 & 4.5 & 13.9 & 13.7 \\
\hline Professional & 4.7 & 5.8 & 17.7 & 17.4 \\
\hline Clerical & 4.3 & 5.5 & 16.7 & 16.5 \\
\hline Technical & 3.9 & 5.0 & 15.4 & 15.3 \\
\hline Craft & 3.4 & 4.3 & 13.7 & 13.5 \\
\hline Personal & 4.1 & 5.2 & 16.1 & 15.9 \\
\hline Sales & 4.0 & 5.1 & 16.0 & 15.8 \\
\hline Plant operatives & 4.2 & 5.3 & 16.5 & 16.3 \\
\hline Others & 3.9 & 4.9 & 15.8 & 15.6 \\
\hline
\end{tabular}

Table 10 Percentage contribution rate needed to achieve same likely worst female pension ratio as the PFA strategy $(95 \%$ confidence level)

\begin{tabular}{|c|c|c|c|c|}
\hline & Equities only & $P F A$ & T-bills only & Bills-bonds \\
\hline All & 21.63 & 14.00 & 23.31 & 20.12 \\
\hline Manual & 21.64 & 14.00 & 23.56 & 20.41 \\
\hline Non-manual & 21.53 & 14.00 & 23.23 & 20.01 \\
\hline Managerial & 21.61 & 14.00 & 23.31 & 20.19 \\
\hline Professional & 21.42 & 14.00 & 23.38 & 20.12 \\
\hline Clerical & 21.56 & 14.00 & 23.38 & 20.17 \\
\hline Technical & 21.71 & 14.00 & 23.54 & 20.41 \\
\hline Craft & 21.80 & 14.00 & 23.75 & 20.76 \\
\hline Personal & 21.64 & 14.00 & 23.56 & 20.42 \\
\hline Sales & 21.55 & 14.00 & 23.67 & 20.55 \\
\hline Plant operatives & 21.54 & 14.00 & 23.73 & 20.59 \\
\hline Others & 21.58 & 14.00 & 23.84 & 20.77 \\
\hline
\end{tabular}

\section{Conclusions}

In this paper, we have analysed the impact of occupation, gender and SAA on DC pension plan outcomes. Our results indicate that the dispersion of DC pension outcomes across occupations depends primarily on the SAA strategy chosen, with relatively large dispersions for equity-based strategies and (usually) much smaller ones for other strategies involving larger bond holdings. The extent to which the pension plan designer must take account of the policyholder's occupation therefore depends to a large extent on the asset strategy that the plan member chooses. This confirms the finding of our earlier 2001 study that modelled the DC pension plan of a typical male worker. 
We also found that there were wide differences in outcome across occupations for the same SAA. For example, with the equities-only strategy, the difference between the highest and lowest median pension ratio was 34 per cent for men and 38 per cent for women. ${ }^{20} \mathrm{We}$ explained these differences in terms of two key parameters explaining the shape of an individual's CSP, namely RCAS and PSA. DC plans benefit most those workers who have the highest career average salary relative to final salary and/or those whose salary peaks earliest in their careers.

These findings are quite unlike those from a conventional DB scheme. Everything else being equal, a DC plan member benefits more from having a higher RCAS and a lower PSA, whereas a DB plan member benefits more from a higher final salary. These differences imply that the choice of scheme has potentially substantial implied wealth transfers, and these transfers are particularly pronounced among male workers (who have larger differences in RCASs than female workers). For example, other things being equal, a move from a DB scheme to a DC scheme for all the workers in the same company implies a major transfer from male managerial and professional workers (since they are likely to have the highest relative final salaries) to male manual workers and to female workers (who tend to have lower relative final salaries, but higher RCASs and lower PSAs). It should be stressed that these transfers are relative: male managerial and professional workers, even with this switch of pension scheme, are likely to end up with larger absolute pensions than male manual workers and most female workers who are members of the same scheme.

Furthermore, there are significant differences between the CSPs of male and female workers within the same occupation, which suggests that key aspects of scheme design (in particular contribution rates) will be gender specific. Of particular interest is the finding that the female median pension ratio is generally higher for the various SAAs than the corresponding male median. For example, with the equities-only strategy, female managerial workers receive a 45 per cent higher median pension ratio than their male counterparts, while for sales staff the difference is lower at 13 per cent. ${ }^{21}$ These results are a direct consequence of the fact that women tend to have higher RCASs than men.

The clear message of our study is that an employee will have been very poorly advised if his or her occupation and gender are not taken into account by those designing their DC pension plan. ${ }^{22,23}$ In future work, we plan to extend our analysis to

${ }^{20}$ Derived from Table 2 (column 1) and Table 7 (column 1), respectively.

${ }^{21}$ Derived from Table 2 (column 1) and Table 7 (column 1), respectively.

${ }^{22} \mathrm{We}$ should be aware of certain weaknesses in our underlying assumptions. For example, we have assumed that individuals remain in employment for their whole careers. In reality, individuals face unemployment risk and hence earnings risk. However, this will impact considerably more on the DB pension than on the DC pension. There are two reasons for this. First, every time a worker changes jobs they experience a portability loss on their DB pension. The pension is based on the leaving salary that is likely to be less than the final salary (even if the leaving salary is uprated to the retirement date to account for inflation, it is uprated by less than the increase in salary). As reported in Blake and Orszag (1997), a typical U.K. worker changing jobs 6 or 7 times in a career suffers a portability loss of around 30 per cent of the final salary pension of a worker with the same salary history who stays his/her whole career with the same employer. Second, the DB pension, depending as it does on the final salary or the average salary in the final three years, is susceptible to earnings risk near retirement. Both these factors bias our analysis against DC schemes. When we also take into account our finding that a well-diversified asset allocation 
allow for such real-world features of actual careers as career breaks, delayed starts to the pension plan, and delayed retirement. For example, in a (fully funded) final salary scheme delaying retirement leads unambiguously to a higher pension. This is not the case in a DC scheme. Despite additional contributions the pension received might actually be lower as a result of falling stock markets and lower annuities that reflect lower interest rates and increased longevity.

\section{References}

Association of Consulting Actuaries (2007) Pension Trends Survey 2007 (July), London.

Becker, G.S. (1964) Human Capital: A Theoretical and Empirical Analysis, with Special Reference to Education, New York: Columbia University Press.

Becker, G.S. (1967) Human Capital and the Personal Distribution of Income, Ann Arbor, MI: University of Michigan Press.

Blake, D., Cairns, A.J.G. and Dowd, K. (2001) 'PensionMetrics: Stochastic pension plan design and valueat-risk during the accumulation phase', Insurance: Mathematics \& Economics 29: 187-216.

Blake, D., Cairns, A.J.G. and Dowd, K. (2003) 'PensionMetrics 2: Stochastic pension plan design during the distribution phase', Insurance: Mathematics \& Economics 33: 29-47.

Blake, D. and Orszag, J.M. (1997) Portability and Preservation of Pension Rights in the UK, Report of the Director-General's Inquiry into Pensions, Vol. 3, Office of Fair Trading, London, July.

Campbell, J., Cocco, J., Gomes, F. and Maenhout, P. (2001) 'Investing retirement wealth: A life-cycle model', in J. Campbell and M. Feldstein (eds) Risk Aspects of Investment-Based Social Security Reform, Chicago and London: University of Chicago Press.

Card, D. (1999) 'The causal effect of education on earnings', in O. Ashenfelter and D. Card (eds) Handbook of Labor Economics (Volume 3) Amsterdam: Elsevier.

Carroll, C. (1997) 'Buffer-stock saving and the life-cycle/permanent income hypothesis', Quarterly Journal of Economics 112: 1-55.

Chamberlain, G. and Hirano, K. (1999) 'Predictive distributions based on longitudinal earnings data', Annales d'Economie et de Statistique 55-56: 211-242.

Cocco, J., Gomes, F. and Maenhout, P. (2005) 'Consumption and portfolio choice over the life cycle', Review of Financial Studies 18: 491-533.

Dickens, R. (2000) 'The evolution of individual male earnings in Great Britain: 1975-95', Economic Journal 110: $27-49$.

Gourinchas, P.-O. and Parker, J. (2002) 'Consumption over the life cycle', Econometrica 70: 47-89.

Hubbard, G., Skinner, J. and Zeldes, S. (1995) 'Precautionary saving and social insurance', Journal of Political Economy 103: 360-399.

Lazear, E. (1981) 'Agency, earnings profiles, productivity and hours restrictions', American Economic Review 71: $606-620$.

Manning, A. and Robinson, H. (2004) 'Something in the way she moves: A fresh look at an old gap', Oxford Economic Papers 56: 169-188.

Mincer, J. (1974) Schooling, Experience and Earnings, New York: Columbia University Press.

with a high equity weighting can, for the same cost as a DB scheme, generate a DC pension that is on average higher than a DB pension and also has good downside protection, then we can conclude that DC schemes do provide a feasible alternative to DB schemes if they are appropriately designed. Samwick and Skinner (2004) reach the same conclusion for 401(k) DC plans in the U.S.

${ }^{23}$ As a final comment, we have shown the importance of the shape of CSPs on the pension outcomes in DC schemes. Yet we have had to construct the CSPs using just eight observations, typically one observation for each 10-year age interval. In addition, these observations are snapshots at a point in time and not what we really need which is the salary experience of a single occupational cohort as it ages over time. The New Earnings Survey is constructing a panel data set, but this only started in 1975 and so full career histories for single cohorts are not yet available in the U.K. 
Murphy, K. and Welch, F. (1990) 'Empirical age-earnings profiles', Journal of Labor Economics 8: 202-229. Office for National Statistics (1998) New Earnings Survey, London: HMSO.

Quantitative Micro Software. EViews User Guide, Irvine, CA: Quantitative Micro Software.

Robinson, H. (2000) 'Are you experienced? Recent British evidence on age-earnings profiles', Applied Economics 35: 1101-1115.

Samwick, A. and Skinner, J. (2004) 'How will 401(k) pension plans affect retirement income?' American Economic Review 94: 329-343.

\section{Appendix A}

\section{Properties of the PensionMetrics asset returns models}

The properties of the real returns on the securities used in the analysis together with salary growth are given in the following table:

\begin{tabular}{lccc}
\hline & Mean (\%) & Standard deviation (\%) & $\begin{array}{c}\text { Correlation with U.K. } \\
\text { salary growth(\%) }\end{array}$ \\
\hline U.K. T-bills & 1.28 & 4.04 & 21.10 \\
U.K. equities & 10.37 & 27.11 & -5.44 \\
U.K. bonds & 1.55 & 13.95 & -34.38 \\
U.K. property & 4.48 & 10.45 & 36.23 \\
U.S. equities & 8.97 & 21.16 & 4.45 \\
U.S. bonds & 2.13 & 16.96 & -1.44 \\
U.K. salary growth & 2.09 & 2.06 & 100 \\
\hline
\end{tabular}

The mean returns in the first column are gross returns; we assume, in our model, that an annual management fee of 1 per cent is deducted from gross returns. The correlation matrix for the returns is presented in the following table:

\begin{tabular}{lcccccr}
\hline & U.K. T-bills & U.K. equities & U.K. bonds & U.K. property & U.S. equities & U.S. bonds \\
\hline U.K. T-bills & 1 & -0.0612 & 0.2563 & 0.2720 & 0.0679 & 0.2603 \\
U.K. equities & -0.0612 & 1 & 0.5441 & 0.1854 & 0.4814 & 0.1568 \\
U.K. bonds & 0.2563 & 0.5441 & 1 & 0.2016 & 0.2335 & 0.3046 \\
U.K. property & 0.2720 & 0.1854 & 0.2016 & 1 & 0.0561 & -0.0358 \\
U.S. equities & 0.0679 & 0.4814 & 0.2335 & 0.0561 & 1 & 0.6818 \\
U.S. bonds & 0.2603 & 0.1568 & 0.3046 & -0.0358 & 0.6818 & 1 \\
\hline
\end{tabular}

\section{Appendix B}

\section{The effect of RCAS and PSA on pension outcomes}

In order to determine the effect of RCAS and PSA on pension outcomes, we need to model the CSP.

Although individuals in the U.K. can start work at 16, we assume that they do not join a pension scheme until 20 and work until 60, so are members of the pension 
scheme for 40 years. Given a raw age $x$, we define a rescaled age, $y$, as:

$$
y=(x-20) /(60-20) \quad x=20,21, \ldots, 60
$$

Thus, $y=0$ for a 20 -year old starting work and $y=1$ for someone who is retiring.

Each CSP in Figures 1 and 2 is modelled as a quadratic function of $y:{ }^{24}$

$$
w(y)=1+k_{1} w_{1}(y)+k_{2} w_{2}(y)
$$

where

$$
\left\{\begin{array}{l}
w_{1}(y)=-1+y \\
w_{2}(y)=-1+4 y-3 y^{2}
\end{array}\right.
$$

The CSP in (B2) shows the individual's real salary (as a function of rescaled age), relative to final real salary. The parameters $k_{1}$ and $k_{2}$ were estimated by least squares methods in EViews, taking account of the missing observations between the eight central ages in the original NES data.

The polynomials in (B3) satisfy the following criteria:

$$
\left\{\begin{array}{l}
w_{i}(1)=0 \quad \text { for } i=1,2 \\
w_{i}(0)=-1 \quad \text { for } i=1,2 \\
\int_{0}^{1} w_{2}(y) \mathrm{d} y=0 \\
\int_{0}^{1} w_{1}(y) w_{2}(y) \mathrm{d} y=0
\end{array}\right.
$$

The first criterion ensures that the final salary is normalised on unity, that is, $w(1)=1$. This normalisation enables us to interpret our results relative to the outcomes that would be achieved under a comparable DB scheme. Recall that we wish to compare the DC pension with a DB benchmark that pays two-thirds of final salary. Accordingly, $w(y)=1$ indicates that the individual is earning a salary equal to final salary at age $y$; similarly, $w(y)=1.1$ indicates that he/she is earning 10 per cent above final salary at age $y$. The normalisation also simplifies comparison of the distributions of the pension ratio for different occupations and gender groups. So when we relate one occupation group to another it is helpful to assume that individuals end up on the same expected (normalised) final salary. Although a male professional is likely to earn a higher salary than a salesman, say, the pension ratio is independent of each occupation's final-salary benchmark, since the pension ratio cancels out the effect of absolute salary levels.

\footnotetext{
${ }^{24}$ The quadratic formulation is common in the labour economics literature and two principal explanations have been put forward to justify the shape. The first is derived from Becker's $(1964,1967)$ and Mincer's (1974) human-capital-earnings function. The second is derived from Lazear's (1981) seniority model of earnings. An example of the second approach is Card who uses a quadratic equation, but with experience replacing age and with an additional years of education variable (Card (1999), Eq. (1)). Other studies use higher-order polynomials: for example, Murphy and Welch (1990); Robinson (2000) and Samwick and Skinner (2004) use fourth-order polynomials, while Cocco et al. (2005) use third-order but also report fifth-order polynomials. We experimented with polynomials up to fifth order, and although they (marginally) fitted the CSP better, the addition of cubic, quartic and quintic terms made negligible differences to the distribution of the pension ratio.
} 
Each year $t$ we assume that an individual's real salary, $s(x, t)$, grows in line with the real increase in national average earnings $(N A E)$, adjusted for a promotional increase:

$$
\begin{aligned}
\Delta \ln s(x, t)= & \Delta \ln N A E(t)+\ln \left(\frac{w((x+1-20) / 40)}{w((x-20) / 40)}\right) \\
& +\Delta v(t)+\Delta \varepsilon(t)
\end{aligned}
$$

where

$$
\Delta v(t)=v(t)-v(t-1) \equiv u(t)
$$

The promotional increase has up to three components:

- a component that is common to all members of the individual's occupation of the same age (the second term on the right-hand side of (B5)),

- an idiosyncratic random component that persists over time (the third term in (B5) which is defined in (B6) as a random walk ${ }^{25}$ with $u(t) \sim$ i.i.d. $\left.N\left(0, \sigma \varepsilon^{2}\right)\right)$,

- and an idiosyncratic random component that is transitory $\left(\varepsilon(t) \sim\right.$ i.i.d. $N\left(0, \sigma_{\varepsilon}^{2}\right)$ which is uncorrelated with $u(t)$, but might be correlated with other variables such as asset returns, thereby allowing for the possibility of a correlation between shocks to human and financial capital). ${ }^{26}$

In line with post-war U.K. experience, the annualised growth rate in real U.K. national average earnings is assumed to be 2 per cent with a standard deviation of 2 per cent. ${ }^{27}$ Further, given that we are modelling the average member of each occupation, we assume that there are no idiosyncratic components (either permanent or temporary) to the promotional increase. ${ }^{28} \mathrm{We}$ are primarily interested in comparing the systematic component of the promotional increase that differs substantially across occupations and between men and women in the same occupation. We therefore assume $\Delta v(t)=0$, $\Delta \varepsilon(t)=0$ and that $\Delta \ln N A E(t)$ grows at a constant rate denoted $g$ below.

The second criterion sets a common initial condition for each polynomial. ${ }^{29}$ The negativity of $w_{i}(0)$ means that the parameters $k_{1}$ and $k_{2}$ have simple interpretations: they measure the gradient (average slope) and hump (degree of curvature) of the CSP, respectively. For this reason we propose to call them the gradient-factor (or G-factor)

${ }^{25}$ Carroll (1997) and Gourinchas and Parker (2002) also model $v(t)$ as a random walk. This is consistent with the empirical evidence of Hubbard et al. (1995) and Chamberlain and Hirano (1999) who estimate a first-order autocorrelation process and find an autocorrelation coefficient close to unity.

${ }^{26}$ Campbell et al. (2001). Cocco et al. (2005, Table 3), however, find that the correlation between the transitory shocks to human and financial capital is statistically insignificant.

${ }^{27}$ This is the assumed productivity growth rate and excludes the promotional increases that influence the shape of the CSPs in Figures 1 and 2. Once the productivity growth rates are allowed for, the humpshaped curves in these figures become elongated Ss. For most workers, real salaries flatten out as retirement approaches but do not actually fall.

${ }^{28}$ This has the additional benefit of avoiding the problem of determining the size of $\sigma_{u}^{2}$ and $\sigma_{\varepsilon}^{2}$ which differ across occupations (Dickens (2000)), although not between males and females within the same occupation (inferred from the conclusions in Manning and Robinson (2004)).

29 This is an arbitrary scaling condition. If we wished to rescale one of the polynomials then we would simply have to apply the reciprocal of the scaling factor to the relevant $k_{i}$ coefficient. 
476

and the hump-factor (or $\mathrm{H}$-factor), respectively. These factors are related to $R C A S$ and $P S A$ as follows:

$$
R C A S=\int_{0}^{1} w(y) \mathrm{d} y=1-0.5 k_{1}
$$

and, provided $k_{2}>0$ :

$$
P S A=20+40 \frac{k_{1}+4 k_{2}}{6 k_{2}}
$$

These results are proved as follows:

Integrating Eq. (B2) and taking into account, (B3) and (B4) gives

$$
\begin{aligned}
R C A S & =\int_{0}^{1} w(y) \mathrm{d} y \\
& =\int_{0}^{1}\left(1+k_{1}(-1+y)\right) \mathrm{d} y \\
& =\left[y+k_{1}\left(-y+0.5 y^{2}\right)\right]_{0}^{1} \\
& =1-0.5 k_{1}
\end{aligned}
$$

which is the same as Eq. (B7).

Substituting from (B3), the CSP function can be rewritten:

$$
w(y)=1+k_{1}(-1+y)+k_{2}\left(-1+4 y-3 y^{2}\right)
$$

Differentiating (B10) with respect to $y$ and setting to zero, we get

$$
w^{\prime}(y)=k_{1}+4 k_{2}-6 k_{2} y=0
$$

from which Eq. (B8) (utilising (B1)) immediately follows, provided $k_{2}>0$.

RCAS is negatively related to the G-factor $\left(k_{1}\right)$. PSA is positively related to the G-factor and, if $k_{1}<0(>0)$, positively (negatively) related to the H-factor $\left(k_{2}\right) .{ }^{30}$ While there is a one-to-one correspondence between the RCAS and the G-factor, indicating that the RCAS is an extremely good proxy for the G-factor, the same cannot be said of the PSA. The relationship between PSA and the H-factor is complicated by the PSA's dependence on $k_{1}$. Further, for a quadratic equation, the PSA as measured by (B8) could differ significantly from the PSA implied by the raw data; in addition, the PSA is sensitive to the degree of polynomial fitted. Despite being less intuitive, the $\mathrm{H}$-factor is therefore a more accurate summary measure of the curvature of the CSP than the PSA, although we continue to make references to the PSA in what follows and in the main text.

The third criterion implies that the second-degree polynomial will have no effect on the accumulation of premiums when the real growth rate in salary (in excess of the merit increases implied by the CSP) is equal every year to the real rate of return on

\footnotetext{
${ }^{30}$ Tables 2 and 7 in the main text show that $k_{1}$ is negative for most CSPs.
} 
fund assets. This result is illustrated in Figure B1 below where we can see that although the addition of the hump changes the shape of the CSP, it does not affect the average salary over the full working lifetime of the individual (since the areas under the two curves are identical). The result is proved mathematically as follows.

For a male worker, let:

$r=$ real rate of return on assets held in the pension fund (assumed constant)

$g=$ real growth rate in salary (assumed constant)

$\theta=(1+r) /(1+g)$

$c=$ contribution rate into the pension fund (assumed to be a constant proportion of salary)

$s(x)=$ real salary at age $x$

$F=$ value of pension fund at retirement.

Then the value of the pension fund at retirement is given by

$$
\begin{aligned}
F= & c \sum_{x=20}^{59} s(x)(1+r)^{60-x} \\
= & c \sum_{x=20}^{59} \frac{w((x-20) / 40)}{w(0)} s(20)(1+g)^{x-20}(1+r)^{60-x} \\
= & c \sum_{x=20}^{59}\left(\frac{w((60-20) / 40)}{w(0)} s(20)(1+g)^{60-20}\right) \\
& \times \frac{w((x-20) / 40)}{w((60-20) / 40)}(1+g)^{x-60}(1+r)^{60-x} \\
= & c \times s(60) \times \sum_{x=20}^{59} w\left(\frac{x-20}{40}\right) \theta^{60-x} \\
\doteq & 40 \times c \times s(60) \times \int_{0}^{1} w(y) \theta^{40(1-y)} \mathrm{d} y
\end{aligned}
$$

If $r=g$, then $\theta=1$ and $F=40 \times c \times s(60) \times \mathrm{RCAS}=F(\theta=1)$, say (using Eq. (B7)). Note that this is independent of $k_{2}$. Furthermore

$$
r\left\{\begin{array}{c}
> \\
= \\
<
\end{array}\right\} g \Rightarrow F\left\{\begin{array}{l}
> \\
= \\
<
\end{array}\right\} F(\theta=1) .
$$

The fourth is an orthogonality criterion. When the coefficients of the polynomial are estimated sequentially, the second-order polynomial added will not significantly affect the values of the previously estimated coefficient of the first-order polynomial because $w_{1}(y)$ and $w_{2}(y)$ are orthogonal. Without these forms for the polynomials, the parameter $k_{1}$ would no longer be directly related to the general gradient or slope of the CSP, for example. 
Having analysed the key features of a CSP, we can now investigate how they influence the pension outcome. From Eq. (B7), a lower value of $k_{1}$ (a lower G-factor) increases the RCAS and, ceteris paribus, increases the pension ratio: the reason is that if contributions are salary-related, relatively higher contributions are invested earlier in the life of the scheme and this increases the size of the DC pension fund relative to the DB pension fund (i.e., the present value of the accrued pension benefits in the DB plan). This result holds irrespective of the relative sizes of the return on assets $(r)$ and the growth rate in salary $(g)$.

By contrast, the impact of $k_{2}$ does depend on the relative sizes of $r$ and $g$. If $r>g$, an increase in $k_{2}$ lowers the pension ratio. This is because a higher $k_{2}$, by increasing the curvature of the CSP, implies a lower starting salary and higher subsequent salaries (for the same $k_{1}$ and hence RCAS). When $r>g$, the effect of a lower starting salary has a bigger impact on the size of the DC pension (in terms of lower cumulative returns, since $r$ is the return on a DC plan) than it does for a DB pension (in terms of lower final salary, since $g$ is the "return" on a DB plan). Since the pension ratio is the ratio of the DC to the DB pension, the pension ratio will generally fall under these circumstances. The opposite result holds when $r<g$.

The results in the previous two paragraphs are summarised in Table B1 and are proved via the following two theorems.

Theorem B1: Suppose $F\left(k_{1}<0\right)$ and $F\left(k_{1}=0\right)$ are the values of the fund for (a given) $k_{1}<0$ and $k_{1}=0$, respectively, and for $k_{2}=0$. Then $F\left(k_{1}<0\right)>F\left(k_{1}=0\right)$, irrespective of the relative sizes of $r$ and $g$.

Proof: Using integration rather than summation, the fourth row of (B12) can be evaluated as follows. For $k_{2}=0$ :

$$
\begin{aligned}
F\left(k_{1}<0\right)= & c \times s(60) \times \int_{20}^{60} w\left(\frac{x-20}{40}\right) \theta^{60-x} \mathrm{~d} x \\
= & 40 \times c \times s(60) \times \int_{0}^{1} w(y) \theta^{40(1-y)} \mathrm{d} y \\
= & 40 \times c \times s(60) \times \int_{0}^{1} f(y)\left(1+k_{1}(-1+y)\right) \mathrm{d} y \\
= & 40 \times c \times s(60) \times \int_{0}^{1} f(y) \mathrm{d} y \\
& +40 \times c \times s(60) \times k_{1} \times \int_{0}^{1} f(y)(-1+y) \mathrm{d} y \\
= & F\left(k_{1}=0\right)+\left\{F\left(k_{1}<0\right)-F\left(k_{1}=0\right)\right\}
\end{aligned}
$$


Table B1 The relationships between the polynomial coefficients of the career salary profile, the return on assets, the growth rate in salary and the pension ratio

1 Regardless of the values of $r$ and $g$, then relative to $k_{1}=0$, a negative (positive) $k_{1}$ will (by increasing (reducing) RCAS) increase (reduce) the ratio of the mean value of the pension fund to final salary and hence the pension ratio. ${ }^{\mathrm{a}}$

2 If $r>g$, then relative to $k_{2}=0$, a negative (positive) $k_{2}$ will (by reducing (increasing) PSA) increase (reduce) the ratio of the mean value of the pension fund to final salary and hence the pension ratio. ${ }^{b}$

3 If $r<g$, then relative to $k_{2}=0$, a positive (negative) $k_{2}$ will (by reducing (increasing) PSA) increase (reduce) the ratio of the mean value of the pension fund to final salary and hence the pension ratio. ${ }^{\mathrm{b}}$

${ }^{\mathrm{a}}$ This follows because $\int_{0}^{1} f(y) w_{1}(y) \mathrm{d} y<0 \quad \forall \theta=(1+r) /(1+g)$.

${ }^{\mathrm{b}}$ This follows because $\int_{0}^{1} f(y) w_{2}(y) \mathrm{d} y\left\{\begin{array}{cc}<0 & \forall \theta>1 \\ >0 & \forall \theta<1\end{array}\right.$.

where $f(y)=\theta^{40(1-y)}$. Since $f(y)>0$ and $(-1+y)<0$ for $0<y<1$, then $\int_{0}^{1}(y)(-1+y) \mathrm{d} y<0$. Hence if $k_{1}<0$, then $\left\{F\left(k_{1}<0\right)-F\left(k_{1}=0\right)\right\}>0$, for all values of $r$ and $g$.

Theorem B2: Suppose $F\left(k_{2}=0\right)$ is the value of the fund for a given $k_{1}(<0)$ and for $k_{2}=0$ and $F_{2}\left(k_{2}>0\right)$ is the value of the fund for the same $k_{1}(<0)$, for a given $k_{2}(>0)$. The corresponding CSPS are depicted in Figure B1 for the cases $k_{1}=-0.1, k_{2}=0.0$, and $k_{1}=-0.1, k_{2}=0.2$. Both CSPS have the same RCAS (see (B7) and the third criterion in (B4)). If $r>(<) g$, then $F\left(k_{2}>0\right)<(>) F\left(k_{2}=0\right)$.

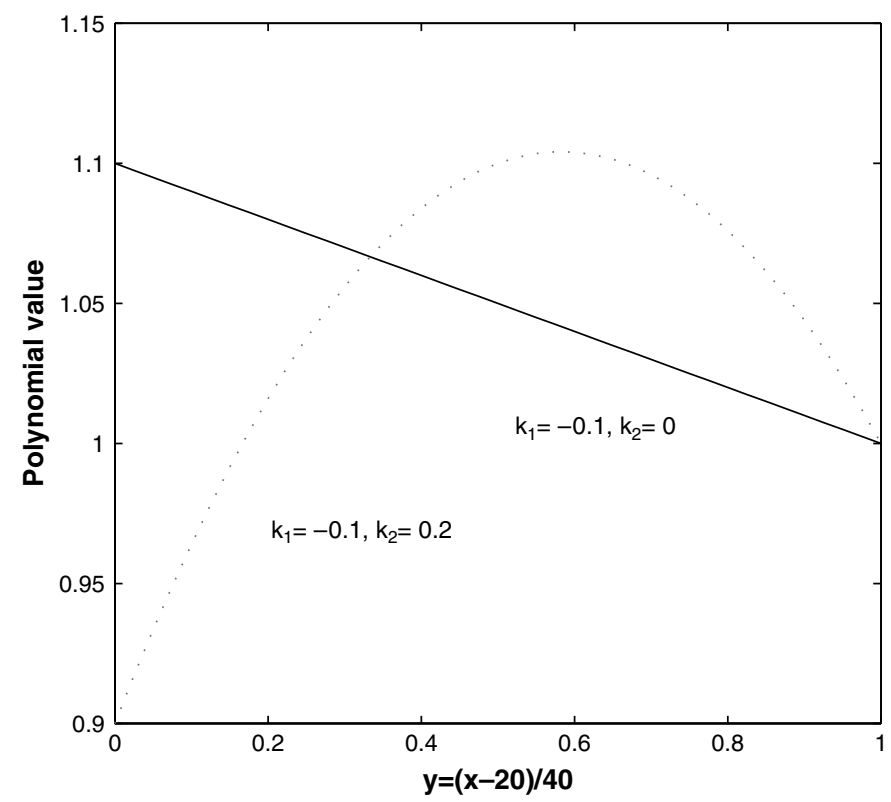

Figure B1. Construction of a career salary profile using basis polynomials. 
Proof: Suppose $r>g$, in which case $\theta>1$. Then from (B13) we have:

$$
\begin{aligned}
F\left(k_{2}>0\right)= & 40 \times c \times s(60) \times \int_{0}^{1} w(y) \theta^{40(1-y)} \mathrm{d} y \\
= & 40 \times c \times s(60) \times \int_{0}^{1} \theta^{40(1-y)}\left(1+k_{1}(-1+y)\right. \\
& \left.+k_{2}\left(-1+4 y-3 y^{2}\right)\right) \mathrm{d} y \\
= & 40 \times c \times s(60) \times \int_{0}^{1} f(y)\left(1+k_{1}(-1+y)\right) \mathrm{d} y \\
& +40 \times c \times s(60) \times k_{2} \times \int_{0}^{1} f(y)\left(-1+4 y-3 y^{2}\right) \mathrm{d} y \\
\equiv & F\left(k_{2}=0\right)+\left\{F\left(k_{2}>0\right)-F\left(k_{2}=0\right)\right\}
\end{aligned}
$$

where $f(y)=\theta^{40(1-y)}$ is a decreasing function of $y$ (i.e., $\left.f^{\prime}(y)<0\right)$.

Using integration by parts, the second integral on the penultimate line of (B16) is evaluated as follows:

$$
\begin{aligned}
\int_{0}^{1} f(y)\left(-1+4 y-3 y^{2}\right) \mathrm{d} y= & {\left[f(y)\left(-y+2 y^{2}-y^{3}\right)\right]_{0}^{1} } \\
& -\int_{0}^{1} f^{\prime}(y)\left(-y+2 y^{2}-y^{3}\right) \mathrm{d} y \\
& =0+\int_{0}^{1} f^{\prime}(y) y(y-1)^{2} \mathrm{~d} y \\
<0 &
\end{aligned}
$$

since $f^{\prime}(y)<0$ and $y(y-1)^{2}>0$ for $0<y<1$. Hence if $k_{2}>0$ and $\theta>1$, then $\left\{F\left(k_{2}>0\right)-F\left(k_{2}=0\right)\right\}<0$.

Conversely, if $r<g$ then $\theta<1$ and $f(y)=\theta^{40(1-y)}$ is an increasing function of $y$, so that $F\left(k_{2}>0\right)>F\left(k_{2}=0\right)$.

The above proofs relate to the pension fund at retirement, rather than the pension ratio at retirement which is the focus of the main text. If the annuity rate at retirement is independent of asset returns, then the above proofs are both necessary and sufficient for proving comparable results for the pension ratio. In practice, the correlation will not be zero (in particular, the annuity yield is likely to be negatively correlated with the return on bonds at the retirement date), although we conjecture that it will be small. So we must conclude that the above theorems, while correct for the pension fund, only hold approximately for the pension ratio. 
The results for $k_{2}$ hold irrespective of the sign of $k_{1}$. Corresponding results can be expressed in terms of the more intuitive (but less reliable) PSA feature of the CSP. However, in this case, the results are not independent of the sign of $k_{1}$. This is because a higher $k_{2}$ raises PSA if $k_{1}<0$, but lowers PSA if $k_{1}>0$ (see Eq. (B8)). Therefore if $r>g$ and $k_{1}<0$, an increase in PSA lowers the pension ratio, while if $r<g$ and $k_{1}<0$, an increase in PSA raises the pension ratio. The opposite results hold if $k_{1}>0$. For most of the CSPs that we analyse, we find that $k_{1}<0$. However, in a small number of cases $k_{1}>0$.

Table B2 presents the $k_{1}$ and $k_{2}$ elasticities for the average male and female worker (whose CSP parameters are given in the first rows of Tables 1 and 6 respectively) and confirms empirically the results in Table B1. The table shows clearly that:

- Lower values of $k_{1}$ increase the mean pension ratio. The male $k_{1}$ elasticities lie between -0.11 and -0.19 depending on the investment strategy. The female $k_{1}$ elasticities are higher in absolute terms and lie between -0.15 and -0.26 . This indicates that a 1 per cent reduction in $k_{1}$ has nearly a 40 per cent greater impact in raising the female mean pension ratio than it has in raising the male pension ratio for a given SAA.

Table B2 Sensitivity analysis of the quadratic coefficients on the mean pension ratio of all male workers and all female workers

\begin{tabular}{|c|c|c|c|c|}
\hline & Equities only & $P F A$ & T-bills only & Bills-bonds \\
\hline Mean value of $\theta^{\mathrm{a}}$ & 1.0823 & 1.0551 & 0.9907 & 0.9922 \\
\hline \multicolumn{5}{|l|}{ All male workers } \\
\hline \multicolumn{5}{|c|}{ Original parameters: $k_{1}=-0.251973, k_{2}=0.655672$} \\
\hline Mean & 4.338462 & 2.297334 & 0.65641 & 0.641311 \\
\hline \multicolumn{5}{|c|}{ Original parameters except: $k_{1}=-0.254493$ (i.e., lowered by $1 \%$ ) } \\
\hline Mean & 4.464343 & 2.399766 & 0.705933 & 0.693149 \\
\hline Elasticity $(\%)$ & -0.1908 & -0.1660 & -0.1082 & -0.1083 \\
\hline \multicolumn{5}{|c|}{ Original parameters except: $k_{2}=0.649115$ (i.e., lowered by $1 \%$ ) } \\
\hline Mean & 4.347896 & 2.300598 & 0.656354 & 0.641263 \\
\hline Elasticity $(\%)$ & -0.2174 & -0.1421 & 0.0085 & 0.0074 \\
\hline \multicolumn{5}{|l|}{ All female workers } \\
\hline \multicolumn{5}{|c|}{ Original parameters: $k_{1}=-0.372147, k_{2}=0.639317$} \\
\hline Mean & 4.756855 & 2.487339 & 0.690149 & 0.674333 \\
\hline \multicolumn{5}{|c|}{ Original parameters except: $k_{1}=-0.3758684$ (i.e., lowered by $1 \%$ ) } \\
\hline Mean & 4.769083 & 2.492971 & 0.691198 & 0.675359 \\
\hline Elasticity $(\%)$ & -0.2571 & -0.2264 & -0.1520 & -0.1522 \\
\hline \multicolumn{5}{|c|}{ Original parameters except: $k_{2}=0.632924$ (i.e., lowered by $1 \%$ ) } \\
\hline Mean & 4.766053 & 2.490522 & 0.690095 & 0.674286 \\
\hline Elasticity $(\%)$ & -0.1934 & -0.1279 & 0.0078 & 0.0069 \\
\hline
\end{tabular}

Note: ${ }^{\mathrm{a}} \theta=(1+r) /(1+g)$, where $r=$ real rate of return on assets held in the pension fund and $g=$ real growth rate in salary. 
- If $r>g$ (i.e., $\theta=(1+r) /(1+g)>1)$, as in the case of the 100 per cent equities and PFA strategies, lower values of $k_{2}$ increase the mean pension ratio. We find negative $k_{2}$ elasticities of -0.14 and -0.22 for males and -0.13 and -0.19 for females, depending on the investment strategy.

- If $r<g$ (i.e., $\theta<1$ ), as in the case of 100 per cent T-bills and mixed bills-bonds, lower values of $k_{2}$ reduce the mean pension ratio. The observed impact is much smaller than in the case where $r>g$, since $\theta$ is much closer to unity for these two SAAs.

\section{About the Authors}

David Blake, a consultant to many organisations in the financial services sector, is Professor of Pension Economics and Director of the Pensions Institute at Cass Business School, London. His recent books include Pension Schemes and Pension Funds in the United Kingdom published by Oxford University Press in 2003, and Pension Economics and Pension Finance, both published by Wiley in 2006.

Andrew Cairns is Professor of Financial Mathematics at Heriot-Watt University and the Maxwell Institute, Edinburgh. He has written extensively on stochastic modelling in insurance and pensions risk management. $\mathrm{He}$ is an active member of the International Actuarial Association (IAA) and is Editor-in-Chief of ASTIN Bulletin - The Journal of the IAA. In 2004 he published the textbook Interest Rate Models: An Introduction (Princeton University Press).

Kevin Dowd is Professor of Financial Risk Management at Nottingham University Business School, where he works with the Centre for Risk and Insurance Studies. His research interests cover pensions, insurance, risk management and financial and monetary economics. His books include Competition and Finance: A Reinterpretation of Financial and Monetary Economics (Macmillan, 1996), Beyond Value at Risk: The New Science of Risk Management (Wiley, 1998) and, most recently, Measuring Market Risk (2nd edn., Wiley, 2005). 